BLS 34, No 1 2008. DOI: http://dx.doi.org/10.3765/bls.v34i1.3587

(published by the Berkeley Linguistics Society and the Linguistic Society of America)

\title{
The Syntax-Pragmatics Interplay in Yaqui
}

\author{
LILIÁN GUERRERO \\ Instituto de Investigaciones Filológicas, Universidad Nacional Autónoma de \\ México
}

\section{Introduction}

Variable word order patterns can result from an interaction of syntactic and pragmatic constrains which may be ranked differently across languages. The aim of this paper is to explore the nature of main clause word order in Yaqui (UtoAztecan) and to locate it within a typological classification, drawing upon Van Valin (1999)'s hypothesis on the interplay of syntax and focus structure. In this proposal, rigid vs. flexible syntax interacts in interesting ways with rigidity vs. flexibility of focus structures, generating four language types. It turns out that Yaqui is fairly rigid in its syntax but flexible in its pragmatics.

The Yaqui language belongs to the Taracahita group of the Southern UtoAztecan family. There are about 15,000 speakers in Sonora (Northwest of México), and approximately 6,000 in Arizona (USA). The analysis presented here is based on data from my own fieldwork on the Sonora dialect. The information is organized as follows: Section 1 outlines a basic morpho-syntactic description of Yaqui simple clauses. In section 2 the theory of the syntax-pragmatics interplay is presented, and in Section 3 the Yaqui typological classification is proposed. Section 4 concludes the paper.

\section{Basic Morpho-Syntactic Properties of Yaqui}

Yaqui is a synthetic/agglutinative verb-final language, and it is generally agreed that nominals show a relatively free order (Escalante 1990; Rude 1996; Dedrick \& Casad 1999; Félix 2000; Guerrero 2006). There is a nominative-accusative case system. In nominal forms, the nominative is unmarked and the accusative is marked by the suffix $-t a$ as shown (1a). There is no dative case, but postpositions like the directional $-u$ indicate oblique core arguments of verbs like nooka 'talk to' in (1b). The accusative and plural suffixes are mutually exclusive. In (1c), the preferred reading is that where the first NP acts as the subject, e.g. the coyotes bit the dogs, but it can also mean the dogs bit the coyotes. The pronominal inventory in (2) ranges in status from fully independent forms, to clitics, to affixes, and 


\section{Lilián Guerrero}

clearly distinguishes among the nominative, accusative, genitive, reflexives, as well as object of postposition functions. ${ }^{1}$

a. U jamut- $\varnothing$ Peo-ta bicha-k.

DET woman-NOM Pedro-ACC see-PFV

'The woman saw Pedro'.

b. U o'ou- $\varnothing$ jamut-ta-u nooka-k.

DET man-NOM woman-ACC-DIR talk-PFV

'The man talked to the woman'.

c. U-me goi-m u-me chu'u-im ke'e-kan.

DET-PL coyote-PL the-PL dog-PL bite-PASTC

'The coyotes bit the dogs'.

(2) Yaqui pronominal system

\begin{tabular}{lllllll}
\hline & Nominative & Accusative & $\begin{array}{l}\text { Object of } \\
\text { postposi- } \\
\text { tion }\end{array}$ & Reflexive & \multicolumn{1}{c}{ Genitive } \\
\hline 1sg & inepo & \multicolumn{1}{c}{ ne } & nee & ne- & ino & in, nim \\
$2 \mathrm{sg}$ & empo ='e & enchi & e- & emo & em \\
$3 \mathrm{sg}$ & aapo & & apo'ik a & a-, ae- & eu, au, emo & a, apo'ik \\
$1 \mathrm{pl}$ & itepo & $=$ te & itom & ito- & ito & itom \\
$2 \mathrm{pl}$ & eme'e ='em & enchim & emo- & emo & em, enchim \\
$3 \mathrm{pl}$ & bempo & & apo'im, am & ame- & emo & bem, bempo'im \\
\hline
\end{tabular}

The strength of the head-final order is seen in the use of postpositions (3a), verbal suffixes (3b), noun-genitive (3c), and adjectives preceding the noun (3b), although relative clauses follow the modified noun (3d). Yaqui is a language where the order of the constituents seems to be determined by the grammatical relation of the NP. For instance, the position of the subject NP is strongly clause-initially in a transitive clause (3a), an intransitive unergative verb (3b), as well as an unaccusative verb (3d), except when it is realized as a pronoun, in which case it may appear in second-position (3c).

$$
\begin{aligned}
& \text { a. Aapo wakas-ta jinu-k bw'awa-ta betchi'ibo. } \\
& \text { 3SG:NOM meat-ACC buy-PFV } \\
& \text { 'She bought meat for the soup'. }
\end{aligned}
$$

Abbreviations: ACC: accusative, CLM: clause linkage marker, DET: determiners, DIR: directional, GEN: genitive, LOC: locative, NEG: negation, NOM: nominative, NMLZ: nominalizer, PST: past, PASTC: past continuative, POT: potential, PRF PFV: perfective, PL: plural, PRES: present, Q: question particle, REL: relative, SG: singular, SUBJ: subject. 
b. Ili uusi-Ø bwaan-taite-k.

little child-NOM cry-start-PFV

'The child started crying'.

c. Joan-ta juubi $=$ ne bicha-k.

Joan-ACC wife $=1 \mathrm{SG}: \mathrm{NOM}$ see-PFV

'I saw John's wife'.

d. Mesa-Ø [em jinu-ka-'u] jamte-k

table-NOM 2SG:GEN buy-PFV-CLM break-PFV

'The table you bought broke down'.

For Yaqui, as for most languages of the family, the structuring of information within the clause has not yet been explored. Dedrick \& Casad (1999:43-45) only comment that topicalization occurs sentence initially (4); in oral narratives, the topical element may be followed by discourse particles like intok 'and' or bea 'then'. It is also said that the unmarked focus position is clause initially.

$$
\begin{aligned}
& \text { Kauwis- } \varnothing \text { intok pocho'o-kun-bicha-u } \quad \text { bwite-k. } \\
& \text { fox-NOM and woods-to-site-DIR } \\
& \text { 'And the fox ran toward the woods.' (Dedrick \& Casad 1999:43) }
\end{aligned}
$$

\section{The Syntax-Pragmatics Interplay Theory}

The central aim of this paper is to provide a first examination of Yaqui main clause word order adhering to the Role and Reference Grammar (RRG) approach (Van Valin 1999, 2005; Van Valin and LaPolla 1997). ${ }^{2}$ Van Valin (1999) defines a typology based on the way languages grammatically organize the expression of focus structure and its interaction with certain syntactic features.

Following Lambrecht (1994), the focus structure of the sentence is understood as the grammatical means which indicate the scope of the assertion in an utterance in contrast to the presupposed or topical part of the utterance. In this approach, there is a distinction between broad focus, i.e., the focus domain encompasses more than one constituent such as predicate or sentence focus, and narrow focus, i.e., the focus domain extends only over a single argument. Predicate focus is universally the unmarked type, and coincides with the traditionally recognized 'topic-comment' organization of information in a sentence: the subject is the topic and the predicate is a comment or assertion about the subject-topic. In the examples below, there is a NP serving as the topic (my car); this is the subject NP in English and Italian. The focus element appears in small caps.

$2 \quad$ For the RRG theory of focus structure based on Lambrecht (1994), I refer to Van Valin and LaPolla (1997:199-241) and Van Valin (2005:68-88). Some studies dealing with this approach include Bently (in press) for Italian and Sicilian; Shimojo (1995, in press) for Japanese; Belloro (2007, in press) for Spanish. 


\section{Lilián Guerrero}

Q: How's your car?
A: a. My car/it BROKE DOWN.
English
b. (la mia macchina) si è ROTTA.
Italian

Sentence focus does not have a topical subject but the focus domain is the entire sentence. In (6), the whole sentence is new information. In English, the subject receives focus stress, while in Italian the subject appears post-verbally and with focus stress.

Q: What happened?
A: a. MY CAR broke down.
English
b. Mi si è rotta la MACCHINA.
Italian

(Lit: 'broke down to me the car')

In narrow focus, the focus domain is a single constituent. In (7), the presupposition 'something broke down' is associated with the sentence, and the assertion is that it is the speaker's car, rather than something else, which broke down. In English, this is signaled by focal stress on the subject or by a cleft construction, e.g., it was my car that broke down. Italian likewise has two options: post-posing the subject or using a cleft construction.

Q: I heard your motorcycle broke down.
A: a. My CAR broke down.
English
a'. It's my CAR that broke down.
b. Si è rotta la mia MACCHINA.
(Lit: 'It is my car that broke down.')
Italian
b'. È la mia MACCHINA che si è rotta.
(Lit. 'It's my car that broke down.')

To complement Lambrecht's approach, Van Valin (1999) includes a distinction between the actual focus domain, that part of the sentence in focus, and the potential focus domain, the part of the sentence in which a focal element may be potentially found. In English, for example, the entire main clause is the potential focus domain; in (5a) the actual focus domain is broke down, in (6a) it is the whole clause my car broke down, and in (7a) it is the subject NP my car.

Van Valin's typology is concerned with comparing languages in terms of the rigidity vs. flexibility of their word order, on the one hand, and the rigidity vs. flexibility of their focus structure on the other, resulting in four language types. The expression of 'syntactic rigidity' refers to a fixed word order for major constituents (see Bently in press for a different notion). The notions of rigid and flexible focus structure refer to restrictions on the potential focus domain: languages in which the potential focus domain is the entire main clause are considered to have a 'pragmatically flexible' structure, whereas those in which the potential fo- 
cus domain is restricted to a subpart of the main clause are considered to show a 'pragmatically rigid' structure.

(8) Typology of the interplay of focus structure and syntax (Van Valin 1999:4)

\begin{tabular}{l|l|l}
\hline & \multicolumn{1}{|c|}{ Rigid Focus Structure } & \multicolumn{1}{c}{ Flexible Focus Structure } \\
\hline Rigid Syntax & (i) French, Toba Batak & (ii) English, Toura \\
& & \\
Flexible Syntax & (iii) Setswana, Italian & (iv) Russian, Polish \\
\hline
\end{tabular}

English and French are prime examples of languages that are rigid in syntactic terms. English, however, exhibits a flexible focus structure, while French has a rigid focus structure. In English main clauses, any clause-internal position can be focal as shown in (9). Due to syntactic rigidity, the English subject must be preverbal in declarative clauses (10a); the pragmatic role of focal subjects is marked prosodically (10b), as is the case with any focal constituent. The examples are from Van Valin's (1991).
a. Kim sent the book to LESLIE yesterday.
b. Kim sent the book to Leslie YESTERDAY.
c. Kim sent THE BOOK to Leslie yesterday.
d. Kim SENT the book to Leslie yesterday.
e. KIM sent the book to Leslie yesterday.

a. What happened? - *BROKE DOWN MY CAR

b. I guess your motorcycle broke down. - MY CAR broke down.

French is a good example of the first type: its syntax and focus structures are both rigid. In general terms, the focus domain cannot be preverbal, and thus preverbal focal subjects are banned (with the exception of $w h$-arguments). Since French syntax is rigid, subjects are strongly disallowed in postverbal position in declarative clauses. According to Lambrecht (1994:22), in a context like that of (5), the focal argument will not be the subject as shown in (11a). As for a narrow focus structure (7), its closest counterpart is a cleft sentence like (11b).

(11) Q: How's your car?
a. J' AI MA VOITURE QUI EST EN PANNE.
I have.1SG my car REL be.3SG in breakdown
'My car broke down'. (lit. I have my car that is broken down)

Q: I heard you motorcycle broke down.
b. C'est MA VOITURE qui est en panne. it be.3SG my car REL be.3SG in breakdown 'It is my car that broke down'. 


\section{Lilián Guerrero}

The third type of language restricts the domain of the assertion to a portion of the clause, but it is relatively flexible in syntactic terms. A good example is Setswana (Bantu) where the potential focus domain is limited to the verb and the following part of the clause. Although this language exhibits a tendency towards SVO order (12a), it requires a postverbal subject if the subject is focal (12b). In (12a), the preverbal argument must be presupposed, while the postverbal argument can be interpreted as topical or focal, depending on the context.

$$
\begin{aligned}
& \text { a. Monna o-bed-its-e mosimane. } \\
& \text { man SUBJ-hit-PRF-MD boy } \\
& \text { 'The/*a man beat a/the boy'. } \\
& \text { b. Ho-filh-il-e MONNA. } \\
& \text { LOC-arrive-PRF-MD man } \\
& \text { 'There arrived A MAN / A MAN arrived'. }
\end{aligned}
$$

Finally, languages of the last type do not limit the focus domain to a portion of the clause: the potential focus domain is extended to the whole clause. Unlike English, however, they do not have any strict syntactic constrains. Russian is a good example, since the linear order of topical and focal elements is not necessarily determined by their grammatical relation to the predicate (13a), which is clear evidence of syntactic flexibility. In presentational intransitive constructions, the subject can precede or follow the verb as in (13b) and (13c), although a preference for a preverbal subject is attested.

$$
\begin{aligned}
& \text { a. Viktora zaščiščajet MAKSIM- } . \\
& \text { Victor.ACC defend.3SG Maxim-NOM } \\
& \text { 'MAXIM defends Viktor'. } \\
& \text { b. MAŠINA SLOMALAC'. } \\
& \text { car break.down.3sG.PST } \\
& \text { '(My) car broke down'. } \\
& \text { c. SLOMALAC' MAŠINA. } \\
& \text { break.down.3SG-PST car } \\
& \text { '(My) car broke down'. }
\end{aligned}
$$

In what follows I propose that Yaqui can be classified as a language with a rigid syntax and a flexible pragmatics. Syntactically, the canonical order of major constituents is SOV, and alternations to this order entail morpho-syntactic and pragmatic consequences. A focal element must occur pre-verbally. Postverbally, topical but not focal elements are allowed. 


\section{Yaqui: Rigid-Syntax and Flexible-Pragmatics}

The default position of topical arguments in Yaqui is clause-initial. This is shown in (14), in which the NP u jamut 'the woman' is the given information, the starting point of the sentence. The default position of focal arguments is preverbal; in (14b) the predicate is the comment or assertion about the subject-topic.
a. Jita-sa u jamut- $\varnothing$ ya'a-Ø?
What-Q DET woman-NOM do-PRES
'What does the woman do?'
b. U jamut / aapo KAFE-TA BWASA- $\varnothing$.
DET woman-NOM 3SG.NOM coffee-ACC toast-PRES
'The woman / she is toasting the coffee'.

The examples in (15) are sentence focus constructions. In the response to the question 'what happened?', the focal information is the entire sentence, meaning there is no topical subject.
a. Jita-sa weye-k?
What-Q go.SG-PFV
'What happened?'.
b. JOAN- $\varnothing$ HERMOSIO-U SIIKA.
Joan-NOM Hermosillo-DIR go.SG.PFV
'John went to Hermosillo'.
c. U JAMUT TOTO'I-M JINU-K.
DET woman hen-PL buy-PFV
'The woman bought the hens'.

The unmarked word order in Yaqui main clauses is compatible with sentence focus and predicate focus. This is also true for presentational sentences like (16) which encode sentence focus.
Inii junaa'a yoawa- $\varnothing$ emo nasuk jiapsi-su-ka-me.
This that animal-NOM 2PL among live-finish-PFV-NMLZ
'This one is the animal which lived among you (pl)'.

Within the information structure perspective adopted here, there is also a contrast between the unmarked narrow focus and the marked narrow focus, the distinction being where the focus falls. For English, if it falls on the final constituent in the clause, then it is unmarked, whereas if it falls to the left of that, it is marked. Thus, narrow focus on a 'direct object' as in (17) is a case of unmarked argument focus. 


\section{Lilián Guerrero}

(17) Q: What did Sally buy?

A: She bought A NEW CAR.

For Yaqui, the potential focus domain can figure at any clause-internal preverbal position. Because it is a verb-final language, this coincides with the whole clause. Moreover, the default position of focal arguments seems to be before the verb, as shown with the focal intransitive subject in (18a) and the focal object in (18b). Although the focal subject in (18c) is in the default position, this structure is not well-formed; focal subjects of transitive sentences must appear clause initially (i.e. marked narrow focus). The focal role is expressed prosodically. The fact that the word order is the same in predicate (14), sentence (15) and narrow focus (18) suggests that Yaqui is flexible in pragmatic terms, but not in syntactic terms.

Q: 'Who did dance?'

a. QueTA-Ø ye'e-k.

Queta-NOM dance-PFV

'Queta danced'.

Q: 'What did the woman buy?

b. U jamut- $\varnothing$ TOTO'I-M jinu-k.

DET woman-NOM hen-PL buy-PFV

'The woman bought hens'.

Q: 'Who did buy the hens?'

c. *Toto'im U JAMUT- $\varnothing$ jinu-k.

hen-PL DET woman-NOM buy-PFV

'The woman bought the hens'.

d. U JAMUT- $\varnothing$ toto'im jinu-k.

DET woman-NOM hen-PL buy-PFV

'The woman bought the hens'.

The discussion has so far dealt with non-contrastive focus. In Yaqui, contrastive focal arguments also appear pre-verbally. The NPs Queta (19a), toto'ita 'hen' (19b), and Mariatau 'to María' (19c) provide the new elements of information in the reply, and contrast with the antecedents which have been introduced previously in discourse. Notice that the contrastive subject and contrastive objects are found in the same position as narrow focused elements (18), which coincides with their canonical position. Focus structure then adapts to a rigid syntax.

(19) Q: Did Lupe dance?

a. e'e QUeTA- $\varnothing$ ye'e-k.

NEG Queta-NOM dance-PFV

'No, Queta danced'. 
Q: 'Did Aurelia buy a dog?'

b. e'e, Aurelia- $\varnothing$ тото'I-TA jinu-k.

NEG Aurelia-NOM hen-ACC buy-PFV

'No, Aurelia bought a hen'.

Q: 'Did Aurelia sell the hen to Lupe?'

c. e'e, Aurelia- $\varnothing$ toto'i-ta MARIA-TA-U nenka-k. NEG Aurelia-NOM hen-ACC María-ACC-DIR sell-PFV 'No, she sold the hen to María'.

Claiming that the Yaqui language represents type-(ii) of Van Valin's typology in (8) does not mean that other non-canonical word orders are banned. In fact, topical subject (20a), accusative (20b) and oblique core arguments (20c-d) can appear postverbally. However, when an accusative or oblique NP (but not a subject NP) follows the verb, two properties must be satisfied: the extraposed NP must be a definite NP, and a clitic pronoun must occur core-internally. ${ }^{3}$
a. тото'I-M jinu-k, u jamut- $\varnothing$.
hen-PL buy-PFV DET woman-NOM
'The woman bought the hens'.

b. María- $\varnothing$ a $a_{i}=$ bicha-k u-ka jamut-ta $a_{i}$.

María-NOM 3SG:ACC $=$ see-PFV DET-ACC woman-ACC

'María saw her, the woman'.

c. Aurelia- $\varnothing$ toto'i-ta $a-u_{i}=$ nenka-k u-e María-ta- $u_{i}$. Aurelia-NOM hen-ACC 3SG-DIR $=$ sell-PFV DET-OBL María-ACC-DIR 'Aurelia sold (her) the hen to María'.

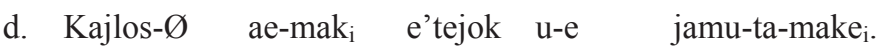
Carlos-NOM 3SG-with talk-PFV DET-OBL woman-ACC-with 'Carlos chatted with her, with the woman'.

How to determine if a NP is definite or specific is still an open question in Yaqui grammar. Although useful, determiners display considerable complexity. For instance, determiners are marked by $-t a$ when modifying an accusative NP (20b), but with $-e$ if the NP is marked by a postposition (20c-d); as with nominal case marking, if the NP is plural, then the determiner is likewise plural, which can be used to mark nominative, accusative or oblique NPs as in (21). Determiners are

\footnotetext{
$3 \quad$ Following Rude (1996:501), a pause between the verb and the extraposed NP is possible but not necessary. However, a detailed analysis regarding the intonation of these constructions would be necessary.
} 


\section{Lilián Guerrero}

commonly optional when modifying a noun, but they become obligatory when either there is no noun (e.g., I bought those), or the noun appears right-detached.

Extraposed NPs need to be topical elements. The clauses in (21a-b) are ruled out since there is a focal unit at the right-edge. The relevant example is in (21c), which is a natural answer to the question 'Who bought the hens?', in which the detached NP must be a topical (but not a focal) unit. A sentence with a topical object exhibits a marked word order. Notice that both the clitic and the determiner before the NP are obligatory, otherwise the construction is ungrammatical (21d-f).

Q: Who bought the hens?
a. *U-me toto'i-m jinu-k, U JAMUT- $\varnothing$.
DET-PL hen-PL buy-PFV DET woman-NOM
'The woman, (she) bought the hens'.

Q: What did the woman buy?
b. *U jamut- $\varnothing$ am ${ }^{*}=$ jinu-k U-ME TOTO'I- $\mathrm{M}_{\mathrm{i}}$. DET woman-NOM 3PL.ACC $=$ buy-PFV DET-PL hen-PL 'The hens, the woman bought them'.

Q: Who bought the hens?
c. U JAMUT- $\varnothing$ $a m_{i}=$ jinu-k u-me toto'i- $m_{i}$. DET woman-NOM 3PL.ACC = buy-PFV DET-PL hen-PL 'The woman bought them, the hens'.
d. *Aurelia
jinu-k ume toto'im.
e. *Aurelia jinu-k toto'im.
f. *Aurelia am jinu-k toto'im.

The above data suggest that Yaqui word order is not entirely rigid in syntactic terms, but rather, non-canonical word order may have some morpho-syntactic consequences. The constraints seen in extraposed structures further support the hypothesis that the preverbal position is the default site of the focal argument in Yaqui.

A detailed analysis of the syntactic, semantic and discourse constrains of postverbal noun phrases in Yaqui goes beyond the scope of this paper (however, see Guerrero and Belloro, in prep). What is evident is that, similar to dislocation in English (Foley 2007:443, Lambrecht 2001:1051), postverbal NPs in Yaqui present a topic NP juxtaposed immediately to the right of the clause and a pronominal element within the clause referring to the topic NP. This right-branching direction (Dryer 1992) is atypical considering Yaqui is a verb-final language.

\section{Final comments}

The analysis presented here suggests that Yaqui is a prime example of a rigid syntax and flexible pragmatics language type. Syntactically, major nominal argu- 
ments are aligned according to their grammatical relation to the predicate, with a canonical word order of SOV. Pronominal arguments and adverbial phrases do show a flexible arrangement within the clause. Pragmatically, the potential focus domain is the main clause and there are no restrictions on where focus can occur pre-verbally. The elements outside the clause are also outside the potential focus domain. This is what is meant by flexible focus structure. An issue which awaits further investigation is the syntactic-pragmatic status of postverbal nominative NPs, accusative and oblique NPs, with the last two requiring a resumptive pronoun inside the main clause.

\section{References}

Belloro, Valeria. 2007. The Syntax-Pragmatic Interface: A study of Spanish Clitic Doubling. Ph. D. diss., University at Buffalo.

Belloro, Valeria. In press. Spanish Datives: Remarks on the Information-Structure Side of the Story. In L. Guerrero, S. Ibañez, and V. Belloro, eds., Studies in Role and Reference Grammar. México: Universidad Nacional Autónoma de México.

Bentley, Delia. 2008. The Interplay of Focus Structure and Syntax: Evidence from two Sister Languages. In R. Van Valin ed., Investigations of the SyntaxSemantics-Pragmatics Interface. 263-284. Amsterdam: John Benjamins.

Dedrick, John and Eugene H. Casad. 1999. Sonora Yaqui Language Structure. Tucson: The University of Arizona Press.

Dryer, Matthew. 1992. The Greenbergian Word Order Correlations. Language 68(1): 81-138.

Escalante, Fernando. 1990. Voice and Argument Structure in Yaqui. Ph.D. diss., The University of Arizona.

Felix, Rolando. 2000. Las relaciones gramaticales en yaqui: un análisis en el marco de la Gramática del Rol y Referencia. M.A. thesis, Universidad de Sonora.

Foley, William. 2007. A Typology of Information Packaging in the Clause. In T. Shopen, ed., Language Typology and Syntactic Description 2: Clause Structure, 362-446. Cambridge: Cambridge University Press.

Guerrero, Lilián. 2006. The Structure and Function on Yaqui Complementation. Studies in Native American Linguistics 54. Munich: Lincom.

Guerrero, Lilián and Valeria A. Belloro. In prep. On Information Structure in the Yaqui Language. Ms.

Lambrecht, Knud. 1994. Information Structure and Sentence Form: Topic, Focus, and the Mental Representations of Discourse Referents. Cambridge: Cambridge University Press.

Lambrecht, Knud. 2001. Dislocation. In M. Haspelmath et al, eds., Language Typology and Language Universals. Berlin: Mouton de Gruyter. 


\section{Lilián Guerrero}

Rude, Noel. 1996. Objetos dobles y relaciones gramaticales: el caso del yaqui. Memorias del Tercer Encuentro de Lingüística en el Noroeste, 491-522. Hermosillo: Editorial Unison.

Shimojo, Mitsuaki. 2009. Focus structure and Beyond Discourse-Pragmatics in Role and Reference Grammar. In L. Guerrero, S. Ibañez, and V. Belloro, eds., Studies in Role and Reference Grammar. México: Universidad Nacional Autónoma de México.

Shimojo, Mitsuaki. 1995. Focus Structure and Morphosyntax in Japanese: wa and $g a$, and Word Order Flexibility. Ph.D. diss., University at Buffalo.

Van Valin, Robert D. 2005. Exploring the Syntax-Semantics Interface. Cambridge: Cambridge University Press.

Van Valin, Robert D. and Randy LaPolla, J. 1997. Syntax. Structure, Meaning and Function. Cambridge: Cambridge: Cambridge University Press.

Van Valin, Robert D. 1999. A Typology of the Interaction of Focus Structure and Syntax. In Raxilina and J. Testelec, eds., Typology and Linguistic Theory: From Description to Explanation, 511-24. Moscow: Languages of Russian Culture.

Lilián Guerrero

SLI-Instituto de Investigaciones Filológicas

Universidad Nacional Autónoma de México

Circuito Mario de la Cueva

Ciudad Universitaria, 04510

México, D.F.

1.guerrero.vlz@gmail.com 